\title{
Carcinoma basocelular invasivo de cuero cabelludo. Caso clínico
}

\author{
A. Taboada; A. Prieto*; I. Couto; B. Brea y E. González
}

Servicios de Cirugía Plástica y Reparadora y de *Neurocirugía. Complejo Hospitalario Universitario de Santiago de Compostela (CHUS). Hospital de Conxo. Santiago de Compostela

\section{Resumen}

El Carcinoma basocelular es el tumor maligno más frecuente de la piel, aunque generalmente no supone un riesgo vital para el paciente. Sin embargo, existen casos en los que su agresividad local es muy importante, llegando a invadir estructuras profundas. Presentamos el caso de una paciente de 62 años de edad, que había sido previamente intervenida en varias ocasiones de basaliomas multifocales en cuero cabelludo. Se presentó con una amplia recidiva local, con invasión de la duramadre y del seno longitudinal superior.

Describimos el caso clínico y el tratamiento quirúrgico realizado conjuntamente por los Servicios de Cirugía Plástica y Neurocirugía.

PALABRAS CLAVE: Carcinoma basocelular. Colgajo frontal. Cáncer de piel. Reconstrucción del cuero cabelludo.

Invasive basal cell carcinoma of the scalp. A clinical case

\section{Summary}

Basal cell carcinoma is the most frequent skin malignant neoplasm, although it doesn't usually compromise a vital risk. However, there are cases in which their local aggressiveness is very important, and it get deep structures. We present a 62 years old female operated several times because multifocal basal cell carcinoma on her scalp. She consulted with a wide local recidive affecting dura mater and superior sagittal sinus.

We show the clinical case and the surgical treatment employed realized by Plastic and Neurosurgery Departments.

KEY WORDS: Basal cell carcinoma. Frontal flap. Skin cancer. Scalp reconstruction.

Recibido: 12-10-09. Aceptado: 25-04-10

\section{Introducción}

El carcinoma basocelular $(\mathrm{CBC})$ es el tipo más común de cáncer cutáneo en individuos caucásicos ${ }^{5}$. Tiene su origen en las células basales, localizadas en la capa más profunda de la epidermis. Su aparición es más frecuente en las zonas expuestas del cuerpo, dada su conocida relación con la exposición prolongada a la radiación solar. Aunque su expansión metastásica a distancia es excepcional ${ }^{13}$, puede en ocasiones producir infiltración local agresiva.

Los CBC en el cuero cabelludo y canto interno son especialmente problemáticos, con recidivas que de aparecer, suelen hacerlo de forma temprana dentro de los 2 primeros años siguientes a la primera cirugía ${ }^{16}$. En la literatura son pocos los casos descritos en los que un CBC localizado en cuero cabelludo cursa con invasión de estructuras intracraneales ${ }^{12}$. Las implicaciones derivadas de este hecho, no sólo ensombrecen el pronóstico para los pacientes afectados, sino que el abordaje necesario para su tratamiento será necesariamente multidisciplinar y requerirá una planificación quirúrgica más allá de la habitual.

\section{Caso Clínico}

Presentamos el caso de una paciente de 62 años ya conocida por los servicios de Neurocirugía y de Cirugía Plástica y Reparadora de nuestro centro que acude nuevamente a consulta por recidiva de un $\mathrm{CBC}$ en cuero cabelludo.

La paciente había sido intervenida once años atrás de forma conjunta por ambos servicios al presentar una tumoración cutánea de unos $5 \mathrm{~cm}$ de diámetro localizada en vértex. No se describen en este primer momento antecedentes personales relevantes. En la RMN y el TC preoperatorios se advierte de signos de infiltración ósea tumoral al menos en dos tercios del espesor del hueso en vértex, sin que en principio se observe infiltración directa de la duramadre y del seno longitudinal superior. Se programa entonces una intervención conjunta por parte de los servicios de Neurocirugía y Cirugía Plástica y Reparadora, realizándose exéresis con márgenes de la lesión cutánea y del hueso subyacente infiltrado por el tumor. La reparación 


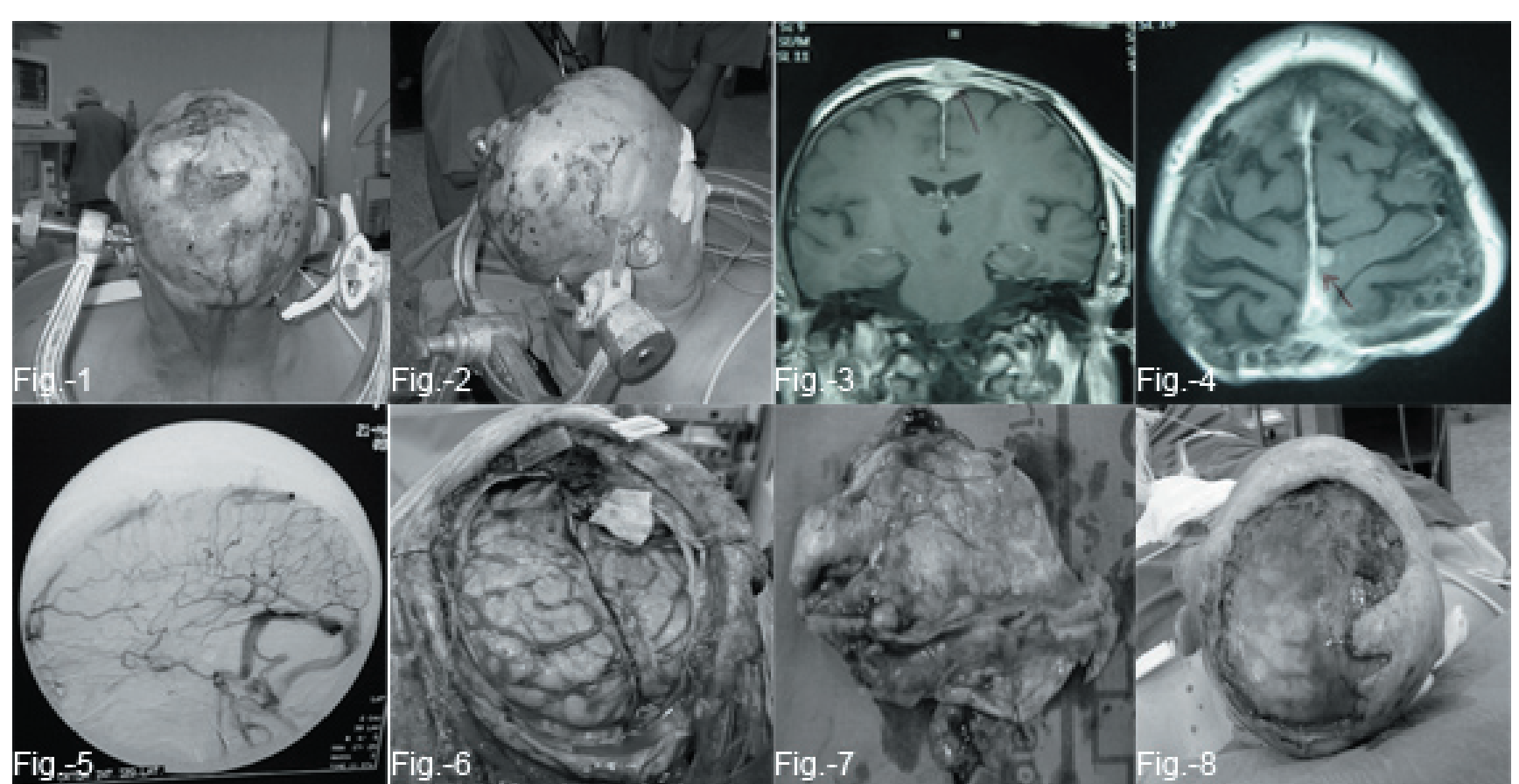

Figuras 1 y 2. Aspecto que presentaba el cuero cabelludo de la paciente previamente a la cirugía. Obsérvense las ulceraciones múltiples correspondientes a los diversos focos tumorales así como las secuelas de colgajos locales realizados en cirugías previas. Figura 3. Neomasa localizada siguiendo el trayecto del seno longitudinal superior. Figura 4. Foco nodular de hipercaptación en el lado izquierdo de la línea interhemisférica cerebral. Figura 5. Imagen angiográfica en la que se observa la obstrucción discontinua del flujo sanguíneo a través del seno longitudinal superior. Figura 6. El tumor fue extirpado intentando alcanzar los máximos márgenes de seguridad posibles. Figura 7. Aspecto de la pieza tumoral una vez completada la resección. Figura 8. La colocación de duramadre liofilizado fue el primer paso en la cobertura del defecto generado.

del defecto se lleva a cabo mediante craneoplastia con tiras de material osteo-integrable y cobertura cutánea mediante colgajos de rotación de cuero cabelludo. La evolución de la paciente tras la intervención fue satisfactoria, no presentó secuela neurológica alguna y fue dada de alta hospitalaria 9 días después de la cirugía. El estudio anatomopatológico informó de $\mathrm{CBC}$ sólido tipo infiltrante que invadía la práctica totalidad del espesor del hueso resecado respetando, en todo caso, los márgenes quirúrgicos.

En los años posteriores la paciente acudió a revisiones periódicas semestrales al servicio de Cirugía Plástica. Tres años y siete años después de la primera intervención fue sometida nuevamente a cirugía para la extirpación de pequeñas tumoraciones cutáneas en cuero cabelludo (región fronto-temporal izquierda y región parietal derecha respectivamente) que se solucionaron mediante el empleo de plastias locales en el primer caso y con injerto de piel de espesor parcial en el segundo. En ambos casos el informe anatomopatológico reveló $\mathrm{CBC}$ con infiltración limitada a tejidos blandos cutáneos.

Once años después de la primera intervención la paciente acude de nuevo a revisión, habiendo transcurrido un año desde la última consulta. Presentaba una tumoración cutánea extensa, ulcerada parcialmente, que ocupaba la práctica totalidad de la región parietal bilateral extendiéndose hacia la región occipital (Figuras 1 y 2). Estimamos la evolución de la nueva tumoración cutánea en 6-7 meses. A la exploración física no se hallaron adenopatías palpables. A pesar de que neurológicamente no se advertía manifestación alguna, debido a los antecedentes presentados por la paciente se realizó una RMN que informó de neomasa de tejido blando con moderada captación de contraste paramagnético siguiendo el recorrido del seno longitudinal superior (Figura 3). Además se observó en los cortes axiales un pequeño foco nodular de hipercaptación en el lado izquierdo de la línea interhemisférica cerebral (Figura 4). La exploración de las cadenas ganglionares mediante RMN descartó signos radiológicos de infiltración ganglionar tumoral en cabeza y cuello. Se realizó panangiografía preoperatoria en la que se observó obstrucción discontinua del flujo sanguíneo a través del seno longitudinal superior y presencia de una importante circulación colateral con drenaje al seno transverso (Figura 5).

De nuevo se decidió programar a la paciente para una cirugía conjunta entre los servicios de Neurocirugía y de Cirugía Plástica y Reparadora. Se realizó exéresis amplia del cuero cabelludo afectado, desde la sutura coronal a aproximadamente la lamboidea, acompañada de trepanación 


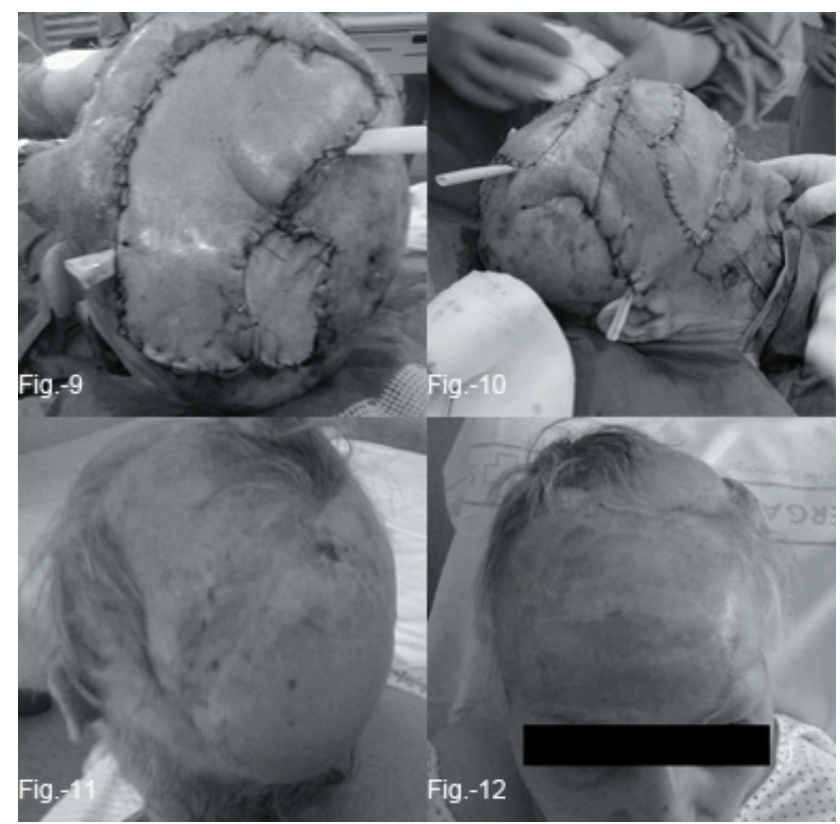

Figuras 9 y 10. El colgajo en isla frontal trazado permitió una cobertura adecuada del injerto de duramadre interpuesto. Su zona donante en la región frontal fue cubierta con un injerto de piel total y en la región occipital se utilizó un injerto de piel parcial como solución temporal. Figura 11. Aspecto a los 16 dias del colgajo en isla frontal y de músculo trapecio. Figura 12. El injerto de piel total ofrece un aspecto estético razonablemente bueno cuando es necesario elevar un colgajo de la región frontal.

biparietal y exposición de la duramadre biparietal y el seno longitudinal superior. Macroscópicamente se observaba infiltración de la dura biparietal y del seno, por lo cual se procedió a la extirpación de las meninges invadidas y del seno longitudinal superior en su tercio medio y en la hoz. La biopsia intraoperatoria realizada informó de márgenes de resección invadidos por el tumor en duramadre parietal izquierda, por lo que se amplió la resección hasta obtener márgenes quirúrgicos libres (Figura 6 y 7). El importante defecto secundario generado tras la extirpación tumoral fue cubierto con un injerto de duramadre liofilizada (Figura 8). Finalmente se procedió al cierre del defecto con un gran colgajo en isla frontal basado en la rama frontal de la arteria temporal superficial, que fue complementado con un injerto de piel parcial a modo de apósito biológico temporal en la región occipital y un injerto de piel total en la región frontal (Figuras 9 y 10). Se realizó además una fijación de la región ciliar al periostio del hueso frontal para evitar la caída de las cejas y mantener así su situación original. Una semana después, el defecto cubierto temporalmente con el injerto de piel parcial de la región occipital, fue definitivamente restaurado mediante la transposición de un colgajo de músculo trapecio.
La evolución de los colgajos empleados para la cobertura fue satisfactoria, y la única complicación registrada a este respecto fue el sufrimiento cutáneo del extremo más distal del colgajo frontal, que evolucionó de forma favorable con tratamiento conservador (Figuras 11 y 12). La paciente presentó en el postoperatorio una secuela parética que afectaba exclusivamente a miembro inferior, con espasticidad 3 sobre 5, sinergia flexora en miembro inferior derecho y pie en actitud de equino-varo con dedos en garra al caminar. El servicio de Rehabilitación de nuestro hospital instauró tratamiento a los 4 días de la intervención con ejercicios de deambulación con bastón y férula anti-equino. A las 2 semanas se infiltró toxina botulínica en los músculos gemelos derechos (100u.i. +100 u.i.), soleo derecho (100u.i.), flexor $1^{\circ}$ dedo derecho (100u.i.) y músculos flexores comunes de los dedos derechos (100u.i.). La paciente fue dada de alta hospitalaria 16 días tras la intervención. Tras cuatro meses de tratamiento rehabilitador la paciente consiguió deambulación correcta sin ayuda de bastón, por lo que fue dada de alta en el servicio de Rehabilitación.

En la actualidad, pasados 3 años y 8 meses de la intervención, la paciente acude semestralmente a consultas de cirugía Plástica y de Neurocirugía. Se realiza RMN de control con cada consulta sin que hasta el momento se hayan podido registrar signos de recidiva tumoral intracraneal. De la misma manera, en el periodo transcurrido no se ha observado nuevo crecimiento tumoral cutáneo en las áreas conservadas de cuero cabelludo ni en los colgajos o injertos empleados para cobertura tras las diferentes intervenciones.

\section{Discusión}

Habitualmente los CBC son tumoraciones cutáneas con un curso clínico poco agresivo. La resección de la tumoración cutánea con pequeños márgenes de seguridad sería, en principio, suficiente para evitar la recidiva tumoral, que se estima en caso de resección macroscópica completa de aproximadamente el 1\% ${ }^{9}$. Las recomendaciones en los márgenes de resección quirúrgica varían entre los $2 \mathrm{~mm}$ y los $10 \mathrm{~mm}$, dependiendo de las zonas donde se localice el tumor, el tamaño del mismo y el tipo tumoral. Goldberg $^{8}$ recomienda resecciones con 2-5mm de margen macroscópicamente libre de tumor excepto para $\mathrm{CBC}$ tipo infiltrantes, como el del caso presentado, en las que sugiere un margen mínimo de 10mm. Este subtipo tumoral ha demostrado tener una mayor actividad celular que las variantes de $\mathrm{CBC}$ no infiltrativas ${ }^{11}$ debida, probablemente, a los hallazgos moleculares específicos en estos tumores tales como mutaciones en p53, disminución en la expresión de la proteína antiapoptótica bcl- $2^{3}$ o mutaciones en los genes c-ras ${ }^{20}$ y c-fos ${ }^{19}$.

En este caso en particular existía afectación ósea y de 
estructuras intracraneales, junto con tres cirugías previas en cuero cabelludo que ocasionaron áreas adyacentes a la lesión tumoral comprometidas con fibrosis cicatricial. Debido a ello, planteamos la realización de biopsias intraoperatorias para que la resección, tanto de las estructuras intracraneales como de los tejidos blandos cutáneos, fuese lo más ajustada posible y nos garantizara un lecho libre de infiltración tumoral. De forma intraoperatoria se confirmaron márgenes libres de invasión tumoral en cuero cabelludo, en las meninges y en la porción de seno longitudinal superior resecados. Respecto al tejido óseo, la necesidad de decalcificación para su estudio histológico hizo que el criterio de resección del mismo se basara en la observación macroscópica del área tumoral en cuero cabelludo y de las meninges infiltradas. El estudio anatomopatológico extemporáneo de la pieza ósea, basándose en los criterios antes mencionados, mostró márgenes de resección libres de infiltración tumoral.

En cuanto al planteamiento meramente ablativo del tumor, era preocupante la infiltración del seno longitudinal superior. Su resección, con el fin de practicar una cirugía con intención curativa, fue posible gracias a que el crecimiento lento del tumor permitió el desarrollo de una amplia circulación venosa colateral a modo de by-pass, evitando el desarrollo postoperatorio de un edema cerebral grave y la aparición de un infarto venoso masivo. Sin embargo somos conscientes de que de no haber sido por la existencia de esta circulación secundaria, la resección completa de los tejidos invadidos no hubiese sido posible de forma completa y nos habríamos visto obligados a practicar una cirugía con fines paliativos.

Durante el acto quirúrgico se desestimó la realización de craneoplastia inmediata, ya que esto hubiera supuesto la necesidad de aportar mayor cantidad de tejidos blandos para la cobertura. Debido al gran tamaño del defecto cualquier pequeña ganancia de tejidos blandos para la cobertura resulta fundamental, por lo que se estimó como opción más apropiada la craneoplastia diferida en esta paciente. En grandes defectos de cuero cabelludo, implicando o no a tejido óseo, es frecuente la cobertura con colgajos libres. En el caso de defectos de menor tamaño, lo razonable es el trazado de colgajos locales ${ }^{7}$. Los métodos de expansión tisular son una opción a considerar en defectos de tamaño intermedio ${ }^{1}$.

La decisión de la cobertura con el colgajo frontal en isla se hizo en base a su sencillez y a la rapidez de la técnica ${ }^{10}$, en contraste con la técnica microquirúrgica que, si bien hubiese requerido un solo tiempo quirúrgico, probablemente hubiese aumentado la morbilidad. Los resultados estéticos (aunque secundarios en este caso) son, además, equiparables con ambas opciones quirúrgicas. Algunos autores opinan que los colgajos libres son la única posibilidad reconstructiva para la cobertura de defectos extensos, principalmente mediante la utilización de colgajos de omentum $^{14}$ o de latissimus dorsi ${ }^{6}$. Nosotros creemos que incluso defectos muy extensos, como en el caso expuesto, se pueden solucionar casi siempre con colgajos locales pediculados sin demasiada repercusión funcional ni estética y resultando además, una opción mucho más sencilla. Aunque no cabe duda de que las técnicas microquirúrgicas ofrecen, en equipos cualificados, una de las mejores opciones reconstructivas, el uso de colgajos pediculados no debe ser desestimado en casos seleccionados.

Respecto a los tratamientos complementarios postquirúrgicos en la paciente debemos decir que, aunque en un principio se consideró la administración de radioterapia postoperatoria, finalmente fue desestimada, tanto en la intervención descrita como en la llevada a cabo 11 años atrás. Ciertos estudios desaconsejan la utilización de radiaciones ionizantes sobre $\mathrm{CBC}$ debido a que se ha comprobado un incremento en las tasa de recidiva ${ }^{18}$. Además, debido a sus efectos iatrogénicos sobre los tejidos blandos, dificulta en gran medida el seguimiento del paciente en cuanto al descubrimiento de nuevas recidivas sobre la piel radiada. Randle, de hecho, considera un tratamiento con radioterapia en $\mathrm{CBC}$ no infiltrante como factor de riesgo para que una recidiva se convierta en una variedad infiltrante y mucho más agresiva ${ }^{15}$, además de incrementar el riesgo de infiltración perineural ${ }^{2}$.

En base a la experiencia aportada por el caso, creemos que los controles mediante técnicas de imagen deberían mantenerse de por vida en aquellos casos de CBC que cursen con invasión de la bóveda craneal. La RMN y la TAC permitirían diagnosticar de forma temprana cualquier nueva recidiva tumoral que pudiese estar ausente o pasar desapercibida en la superficie del cuero cabelludo antes de que se manifestase de forma clínica en el paciente. A pesar de la relativa benignidad de los basaliomas en cuanto a su curso lento y predecible y a los años transcurridos sin recidiva tumoral (11 años la paciente descrita), pensamos firmemente que el riesgo de un nuevo crecimiento tumoral, ya sea por recidiva o por neoformación, nunca se elimina de forma completa, especialmente cuando el tipo histológico es de la variedad infiltrante.

En pacientes con $\mathrm{CBC}$ se ha descrito que el pronóstico vendrá determinado por una serie de factores dependientes de las características morfológicas e histológicas del propio tumor. Son factores que, en principio, contribuyen a una mayor agresividad tumoral un tamaño mayor de 3 centímetros de diámetro, localización en el tercio medio facial, la escisión incompleta de una tumoración previa, un curso evolutivo prolongado sin recibir tratamiento adecuado, la variante histológica infiltrante y la presencia de invasión perivascular o perineural ${ }^{21}$. La diseminación metastásica a ganglios regionales es relativamente infrecuente, aunque posible. La diseminación a distancia de metástasis por un $\mathrm{CBC}$ constituye una rareza por sí misma y se han descrito 
casos contados en la literatura ${ }^{13}$. Según nuestra opinión, en el caso concreto de los $\mathrm{CBC}$ que cursen con invasión intracraneal, el pronóstico para el paciente vendrá determinado principalmente por el grado de invasión y por las estructuras intracraneales invadidas. De forma excepcional los $\mathrm{CBC}$ con infiltración intracraneal cursan con invasión del tejido parenquimatoso ${ }^{20}$, sin embargo la invasión intracraneal de la tumoración incluso sin la infiltración de estructuras meníngeas, puede por su efecto masa, provocar la muerte del paciente ${ }^{12}$.

\section{Conclusiones}

Los tumores cutáneos invasivos de la bóveda craneal suponen, en ocasiones, un desafío tanto terapéutico como reconstructivo.

Dentro de las distintas opciones técnicas y, aunque los colgajos libres suponen generalmente la mejor opción quirúrgica, no deben descartarse el uso de colgajos locales pediculados. En casos seleccionados, aportan resultados funcionales y estéticos similares, suponiendo un menor tiempo quirúrgico y una menor morbilidad al paciente.

En casos como el expuesto en el que la resección oncológica debe, sin lugar a dudas, ir seguida de una reconstrucción inmediata y segura, la colaboración interdisciplinar debe ser la norma.

\section{Bibliografía}

1. Balaguer, J., Landin, L., Hidalgo, JC.: Reconstrucción del cuero cabelludo mediante colgajo de galea frontal: a propósito de un caso. Cir plast iberolatinoam 2006; 32: 49-53.

2. Brown, C., Perry, A.E.: Incidence of perineural invasion in histologically aggressive types of basal cell carcinoma. Am J Dermatopath 2000; 22: 123-125.

3. Crowson, A., Magro, CM., Kadin, ME., Stranc, M.: Differential expression of the bcl-2 oncogene in human basal cell carcinoma. Hum Pathol 1996; 27: 355-359.

4. De Rosa, G., Staibano, S., Barra, E., et al.: p53 protein in aggressive and nonaggressive basal cell carcinoma. J Cutaneous Pathol 1993; 20: 429-434.

5. Diepgen, TL., Mahler, V.: The epidemiology of skin cancer. Br J Dermatol 2002; 146 (Suppl): 1-6.

6. Fattah, A., Pollock, J., Maheshwar, A., Britto, JA.: Big Bad BCCs: craniofacial resection and reconstruction for atypical basal cell carcinoma. J Plast Reconstr Aesthet Surg 2009; XX: 1-9 [Epub ahead of print].

7. Gevorgyan, A., Yaghjyan, GV., Shamakhyan, HV., Danielyan, AM., Sahakyan, AB.: Supraorbital Artery Myocutaneous Island Flap for Forehead Defect Reconstruction. J Craniofac Surg 2008; 19: 513-516.

8. Goldberg, DP.: Assessment and surgical treatment of basal cell skin cancer, Clin Plast Surg 1997; 24: 673-686.
9. Griffiths, RW., Suvarna, SK., Stone, J.: Do basal cell carcinomas recur after complete conventional surgical excision? Br J Plast Surg 2005; 58: 795-805.

10. Guerrissi, J.O.: Reconstruction of large defects in the scalp with fasciocutaneous flaps. Scand J Plast Reconstr Surg Hand Surg 1999; 33: 217-224.

11. Horlock, N., Wilson, G.D., Daley, F.M., et al.: Cellular proliferation characteristics do not account for the behaviour of horrifying basal cell carcinoma. A comparison of the growth fraction of horrifying and non-horrifying tumours. Br J Plast Surg 1998; 51: 59-66.

12. Kovarik, CL., Stewart, D., Barnard, JJ.: Lethal basal cell carcinoma secondary to cerebral invasion. J Am Acad Dermatol 2005; 52: 149-151.

13. Lo, J.S., Snow, S.N., Reizner, G.T., Mohs, F.E., Larson, P.O., Hruza, G.J.: Metastatic basal cell carcinoma: report of twelve cases with a review of the literatura. J Am Acad Dermatol 1991; 24: 715-719.

14. Navarro, F., Riba, B., Guerra, R.: Reconstrucción de cuero cabelludo con colgajo libre de Omentum. Rev Esp Cirug Oral y Maxilofac 2004; 26: 249-256.

15. Randle, H.W., Roenigk, R.K., Brodland, D.G.: Giant Basal Cell Carcinoma (T3). Who is at risk? Cancer 1993; 72 : 1624-1630.

16. Robins, P.: The Skin Cancer foundation. 1-800-SKIN490 www.skincancer.org, 2007.

17. Schroeder, M., Kestlmeier, R., Schlegel, J., Trappe, AE.: Extensive cerebral invasión of a basal cell carcinoma of the scalp. Eur J Surg Oncol 2001; 27: 510-511.

18. Smith, S., Foley, E.H., Grande, D.J.: Use of Moh's micrographic surgery to stablish quantitative proof of heightened tumor spread in basal cell carcinoma recurrent following radiotherapy. Journal Dermatol Surg Oncol. 1990; 16: 1012-1016.

19. Urabe, A., Nakayama, J., Taniguchi, S., Kuroki, R., Hori, Y.: Expression of the fos oncogene in the basal cell carcinoma. J Dermatol Sci 1994; 8: 50-53.

20. Van der Schroeff, J., Evers, LM., Boot, AJM., Bos, JL.: Ras oncogene point mutations in basal cell carcinomas and squamous cell carcinomas of the human skin. J Invest Dermatol. 1990; 94: 423-425.

21. Walling, H.W., Fosko, S.W., Geraminejad, P.A., Whitaker, D.C., Arpey, C.J.: Aggressive basal cell carcinoma: presentation, pathogenesis, and management. Canc Metastasis Rev 2004; 23: 389-402.

Taboada, A.; Prieto, A.; Couto, I.; Brea, B.; González, E.: Carcinoma basocelular invasivo de cuero cabelludo. Caso clínico. Neurocirugía 2010; 21: 396-400.

Correspondencia: Dr. Antonio Taboada Suárez. Servicio de Cirugía Plástica y Reparadora. Hospital de Conxo. C/ Ramón Baltar s/n. 15706 Santiago de Compostela (A Coruña) atsuarez1@hotmail.com 